\title{
Assessing the Awareness and Knowledge on the Use of Probiotics by Healthcare Professionals in Nigeria
}

\author{
Chukwu Otuto Amarauche* \\ 'Pharmaceutical Services Department, Nigeria National Assembly Medical Center, Abuja Nigeria. ${ }^{2}$ Community Health and Human Enhancement Initiative, Abuja, Nigeria \\ +2347066091019, *otutoc@yahoo.com
}

\begin{abstract}
Objective: To assess the awareness and knowledge of healthcare professionals in Nigeria on probiotics. Methods: Participants were randomly sampled from major healthcare institutions in Nigeria's capital. Semi-structured questionnaires were administered. Descriptive statistics was used in data analysis. Results: Results showed limited knowledge and awareness of probiotic products by the healthcare professionals assessed. Amongst the participants, pharmacists were more knowledgeable. Conclusion: The findings showed a limited knowledge on probiotics thus limiting their use. Knowledge on probiotics can be improved through seminars, update lectures, incorporating the topic in the curricula of upcoming professionals, amongst others. Pharmacists can also educate other professionals as they are widely regarded as drug experts and have shown to be more informed on this issue.
\end{abstract}

Key words: Awareness, Knowledge, Probiotics, Healthcare Professionals, Nigeria.

Key message: Healthcare professionals in Nigeria seem not to be aware of probiotic use despite their advantages. Improving this knowledge will help in increasing positive outcomes for diseases in which probiotics may be beneficial such as diarrhea.

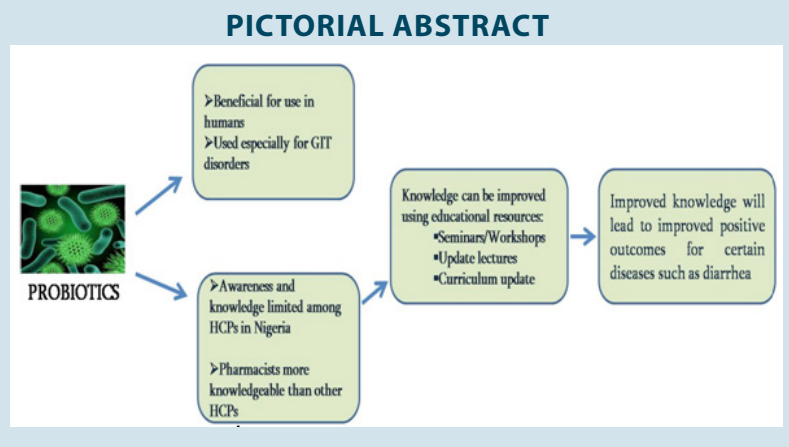

Correspondence :

Chukwu Otuto Amarauche

Pharmaceutical Services Department

${ }^{1}$ Nigeria National Assembly Medical Center, Abuja Nigeria. ${ }^{2}$ Community Health and Human Enhancement Initiative, Abuja, Nigeria.

Phone: +234 (0) 7066091019

E-mail: otutoc@yahoo.com

DOI: 10.5530/jyp.2016.1.12

\section{INTRODUCTION}

The gastro-intestinal tract (GIT) of an adult human contains up to 500 different species of micro-organisms existing in mutual interdependence with the host and offering benefits such as protection against infection from other microbes, stimulating immune function, amongst others. ${ }^{1,2}$ A decrease in this normal endogenous flora, mainly due to antibiotic use may lead to microbial imbalance which may result in gastroenteritis and diarrhea. ${ }^{3,4}$ Addressing this imbalance may involve external supplementation with beneficial micro-organisms in the form ofprobiotics which are live microorganisms which confer a health benefit on the host when administered in adequate amounts. ${ }^{5}$ These agents have been mostly used in the treatment of GIT diseases, ${ }^{6}$ such as infectious diarrhea, inflammatory bowel disease, irritable bowel syndrome and Clostridium difficile infection. ${ }^{7}$ They improve the health of the GIT by stimulating mucosal immune function, antagonizing and competing with potential pathogens, improving digestion amongst others. ${ }^{8,9}$ They are generally consumed as fermented foods such as yogurts, however, probiotics supplements are now being formulated in the form of tablets, capsules, granules and liquids. Specific strains of Lactobacillus and Bifidobacterium species are the most commonly used. ${ }^{8}$ Probiotics have been found effective in the management and treatment of diarrhea, ${ }^{10}$ eradication of Helicobacter pylori infection, ${ }^{8}$ lactose intolerance, ${ }^{11}$ and oral candidiasis. ${ }^{12}$

Some studies have shown a high level of awareness, knowledge and consumption of probiotic supplements in countries with advanced healthcare delivery systems such as Australia, ${ }^{13}$ Canada ${ }^{14}$ and the United States. ${ }^{15}$ However, this seems not to be the case in developing countries like Nigeria. Literature search revealed a paucity of information on the subject of probiotics in Nigeria. Given the important benefits that the use of probiotics may offer in the treatment of certain medical conditions, it may be important to assess the awareness and knowledge level of HCPs on this subject and seek out ways to improve their knowledge and use of these products. Therefore, the aim of this study was to assess the level of awareness and knowledge on probiotics by HCPs in Nigeria.

\section{METHODS}

The study was set in Abuja, the capital city of Nigeria and included four different categories of HCPs: Physicians, Pharmacists, Dentists and Nurses. Semi-structured questionnaires were administered to the randomly sampled respondents who were all qualified health practitioners from the major Government and private health institutions in Abuja Metropolis, Nigeria. The participants gave oral informed consent prior to administration of the questionnaires. The questionnaires were administered at the place of work to each participant. The questionnaires addressed the demographics such as age, gender and years of practice; awareness and knowledge about probiotics and their availability; concerns on the use of probiotics and willingness to obtain more information about probiotics. Data analysis was carried out using IBM SPSS Statistics version 21. Descriptive statistics was used. P values less than 0.05 were considered to be significant.

\section{RESULTS}

Out of the 300 questionnaires distributed, 221 were returned, giving a return rate of $73.67 \% .43 .4 \%$ (96) of the respondents were males while $56.6 \%$ (125) were females. $33 \%$ of the respondents were aged between 21 to 30 years, $35.3 \%$ were aged between 31 to 40 years, $22.2 \%$ of the respon- 
dents were aged between 41 to 50 years while $9.5 \%$ of the respondents were over 50 years of age.

$72.4 \%$ (160) of the respondents stated that they are aware of the term probiotics however only $25.8 \%$ (57) stated that they have ever prescribed or recommended the use of any probiotic product. As a means of comparison, $63.8 \%$ (141) of the respondents stated that they prescribe or recommend the use of antibiotics regularly.

Even though $80.1 \%$ (177) of the respondents stated that the use of probiotics may be beneficial for patients only $33 \%$ (73) of the respondents are aware of any probiotic products in the Nigerian pharmaceutical market. When asked about what they thought might be the constituents of probiotics, $65.6 \%$ (145) of the respondents stated that probiotics contain live microorganisms, $14.5 \%$ (32) stated they were synthesized drugs, $14.9 \%$ (33) stated that probiotics are natural plant products while $5 \%$ (11) did not give any response. Only $16.3 \%$ (36) of the respondents stated that they were aware of any research on probiotics.

The respondents were asked to raise any concerns that they may have on the use of probiotics. Some of the concerns raised by the respondents include: Probiotics may be unsafe for use as they may lead to infection of patients. $33.9 \%$ of the respondents raised this concern. $8.6 \%$ of the respondents stated that probiotics may not have any proven beneficial effects on patients. $10.4 \%$ of the respondents stated that probiotics may be carcinogenic while $15.4 \%$ stated that these products may not be easily approved for use by drug regulatory agencies in Nigeria such as the National Agency for Food and Drug Administration and Control (NAF$\mathrm{DAC}$ ). Availability and affordability was the major concern raised by the respondents as $40.3 \%$ of the respondents stated that these products may not be readily available and even if they were, they may not be affordable. All the respondents indicated that they would need more information on probiotics. The respondents stated that they would prefer to obtain information on probiotics through different means such as peer-reviewed journals $(32.6 \%)$, medical textbooks (65.2\%), medical websites (70.6\%), medical representatives of pharmaceutical companies (33\%) and through seminars and workshops (33.5\%).

Within the HCPs, Pharmacists seemed to be more aware and knowledgeable on probiotics and probiotic products in Nigeria. Out of the $72.4 \%$ (160) of respondents that were aware of the term probiotic, $36.9 \%$ (59) were pharmacists while physicians, nurses and dentists consisted of $28.8 \%(46), 20 \%$ (32) and $14.4 \%$ (23) respectively.

Out of the $33 \%$ (73) of respondents that were aware of probiotic products available in Nigeria, $57.5 \%$ (42) were pharmacists while physicians, nurses and dentists consisted of $30.1 \%$ (22), $11 \%$ (8) and $1.4 \%$ (1) respectively.

Out of the $25.8 \%$ (57) of the respondents that have prescribed or recommended the use of probiotics, $52.6 \%$ (30) are pharmacists while $35.1 \%$ (20) and $12.3 \%$ (7) were physicians and nurses respectively. The results suggested that none of the dentists have prescribed or recommended the use of probiotics.

Out of the $65.6 \%$ (145) that stated that probiotics contained live microorganisms, $39.3 \%$ (57) were pharmacists, $28.3 \%$ (41) were physicians, $18.6 \%$ (27) were nurses while dentists constituted $13.8 \%(20)$.

\section{DISCUSSION}

The results show that HCPs in Nigeria seem to have limited awareness and knowledge on probiotics. Probiotic research and use in Nigeria seem to be limited and the knowledge of HCPs on probiotic research in other parts of the world seems to be limited as well. This may be due to limited access to peer-reviewed journals which usually require paid subscription for access. Despite the large volume of information available on medical journals and websites on probiotics, all the respondents showed a desire to still gain more information on probiotics. This may be an indication that gaps still exist in the area of health information dissemination within HCPs in Nigeria. It may also be that HCPs in Nigeria may not always be willing to update their knowledge on existing and current trends in health and healthcare delivery in the globe. This is because over $70 \%$ of the respondents indicated that they would want to gain more information from websites of which information on probiotics is readily available. However, they may not be willing to access these web pages and gain more information. To improve the level of awareness and knowledge of probiotics among HCPs in Nigeria may require incorporating the subject into the university curricula so that upcoming HCPs will have background knowledge on the issue. Organizing seminars and workshops on probiotics may be helpful in increasing knowledge on the subject. Incorporating the topic as part of the update lecture series for professional development of different HCPs in Nigeria may also be an avenue for increasing awareness and knowledge of HCPs on probiotics. Medical representatives of pharmaceutical companies that formulate these products may also help in improving awareness and knowledge as $33 \%$ of the respondents indicated that they would want to obtain more information from them.

Among the concerns raised on the use of probiotics was the possibility of the products being unsafe as they may lead to infection of patients. Even though some cases of fungemia and bacteria sepsis have been reported, evidence suggests that such reported cases of fungemia and bacterial sepsis due to the use of probiotics may have been observed in patients with compromised immune system or patients suffering from chronic diseases. ${ }^{16}$ Even though sepsis due to probiotic use arises, it can be resolved with administration of appropriate antimicrobial therapy. ${ }^{16}$ Other concerns raised such as the possibility of probiotics being carcinogenic seem to have no supporting research evidence. Instead, there are suggestions that they may be effective in delaying the onset of and recurrence of cancers. ${ }^{17}$ The availability of some probiotic products in the Nigerian market indicates that approval by drug regulatory bodies such as NAFDAC may not be an issue so long as the products meet the required quality assurance specifications. The major concern of availability and affordability raised by the respondents may be a further indication of limited knowledge on these products as some probiotic products are in existence in Nigeria. Products containing strains of Lactobacillus acidophilus, Bifidobacterium infantis, Enterococcus faecium and Saccharomyces boulardii are readily available in community pharmacies within the study area at prices which the researcher considers to be affordable. Even though affordability may be a relative term, the price for these probiotic products are similar to the price of other medications which an average Nigerian may be always able to afford when in need of.

Amongst the different HCPs, pharmacists showed to have more awareness and knowledge on probiotics. Since the pharmacist is widely regarded as the drug expert, it seems the onus lies on them to educate other HCPs on these products within the healthcare setting while not neglecting their personal responsibility of updating their knowledge regularly.

\section{CONCLUSION}

HCPs in Nigeria seem to have limited awareness and knowledge of the use of probiotics. The awareness and knowledge of these beneficial products can be improved through educational tools and resources such as seminars and workshops, update lectures for continuing professional development amongst others. Pharmacists can also educate other HCPs as they are widely regarded as drug experts and seem to be more informed on this issue.

My profound gratitude to Kate Asogwa, Nwabugo Akujuaobi and Godwin Emerie Asogwa for helping me with distribution of questionnaires for data collection 


\section{SUMMARY}

- Probiotics are live microorganisms which confer a health benefit on the host when administered in adequate amounts

- Healthcare Professionals in Nigeria seem not to be adequately aware and knowledgeable on probiotics and its use. Out of the Healthcare Professionals, pharmacists showed to be more aware and knowledgeable and should serve as a drug information link between other healthcare professionals

- Knowledge can be improved through educational resources such as seminars and update lectures

- Improved knowledge and awareness will in turn help in improving outcomes for diseases where probiotic administration may be beneficial

\section{ABBREVIATIONS USED}

GIT: Gastro-Intestinal Tract, HCPs: Healthcare Professionals, IBM: International Business Machines Corporation, SPSS: Statistical Package for the Social Sciences, NAFDAC: National Agency for Food and Drug Administration and Control

\section{ABOUT AUTHOR}

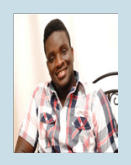

Chukwu Otuto Amarauche is a Pharmacist/Researcher working at the Nigeria National Assembly Medical Center and Community Health and Human Enhancement Initiative. He graduated with a Bachelor of Pharmacy Degree from the University of Nigeria and has a diploma in health management from the World Bank Institute and USAID certification in Logistics Management for Health Commodities. His interests lie in global health policy and public health where he is working towards obtaining a Masters Degree. He is working on various avenues that can be used in improving the health sector in Nigeria.

\section{REFERENCES}

1. Sherman PM, Cabana M, Gibson GR, Koletzko BV, Neu J, Veereman-Wauters G, et al. Potential roles and clinical utility of prebiotics in newborns, infants, and children: proceedings from a global prebiotic summit meeting, New York City, June 27-28, 2008. J Pediatr 2009;155 (5): S61-70.

2. Eckburg PB, Bik EM, Bernstein CN, Purdom E, Dethlefsen L, Sargent M, et al. Diversity of the human intestinal microbial flora. Science 2005; 308 (5728):1635-8.

3. Marteau PR, De Vrese M, Cellier CJ, Schrezenmeir J. Protection from gastrointestinal diseases with the use of probiotics. Am J Clin Nutr 2001; 73 (suppl): 430S-6S.

4. Berger A. Science commentary: Probiotics. BMJ Volume 324; 8; June 2002.

5. Food and Agriculture Organization/World Health Organization. Evaluation of health and nutritional properties of probiotics in food including powder milk with live lactic acid bacteria. Food and Agriculture Organization of the United Nations and World Health Organization Report, 2001. ftp://ftp.fao.org/docrep/fao/009/ a0512e/a0512e00.pdf

6. Binns C, Lee MK. The use of Probiotics to Prevent Diarrhea in Young Children Attending Child Care Centers: A Review. J Exp Clin Med 2010; 2(6): 269-273.

7. Floch MH, Walker WA, Madsen K, Sanders ME, Macfarlane GT, Flint HJ, et al. Recommendations for Probiotic Use-2011 Update. J Clin Gastroenterol 2011; 45: S168-S171.

8. World Gastroenterology Organization. Probiotics and Prebiotics. World Gastroenterology Organization Practice Guideline, May 2008.

9. Shinde PB. Probiotic: An Overview for Selection and Evaluation. Int J Pharm Pharm Sci 2012: 4: 14-21.
10. Simadibrata M, Ndraha S, Tedjasaputra R, Syam AF Aan Santi AF, Rani A. Revealing the effect of probiotic combination: Lactobacillus rhamnosus and Lactobacillus acidophilus (Lacidofil囚) on acute diarrhea in adult patients. J Clin Med Res2013; 5: 23-28.

11. Montes RG, Bayless TM, Saavedra JM, Perman JA. Effect of milks inoculated with Lactobacillus acidophilus or a yogurt starter culture in lactose-maldigesting children. J Dairy Sci.1995; 78 (8): 1657-64.

12. Sunayana M, Alekhiya K, Preethi A, Kumar S, Prabu D. Awareness about Probiotics in Dental, Medical Professionals and Health Care Providers. Unique J Med Dent Sci 2013; 01;36-40.

13. Braun LA, Tiralongo E, Wilkinson JM, Spitzer O, Bailey M, Poole S, et al. Perceptions, use and attitudes of pharmacy customers on complementary medicines and pharmacy practice. BMC Complement Altern Med 2010; 10:38.

14. Bridgman SL, Azad MB, Field CJ, Letourneau N, Johnston DW, Kaplan BJ et al. Maternal perspectives on the use of probiotics in infants: a cross-sectional survey. BMC Complement Altern Med 2014; 14:366

15. Owens C, Toone T, Steed-Ivie M. A Survey of Dietary Supplement Knowledge, Attitudes, and Use in a Rural Population. J Nutr Food Sci 2014; 4: 304.

16. Boyle RJ, Robins-Browne RM, Tang MLK. Probiotic use in clinical practice: what are the risks? Am J Clin Nutr 2006; 83:1256-64.

17. Aso Y, Akaza H, Kotake T, Tsukamoto T, Imai K, Naito S. Preventive effect of a Lactobacillus casei preparation on the recurrence of superficial bladder cancer in a double-blind trial. The BLP Study Group Eur Urol 1995، 27: 104-9. 